\title{
Amostra de ciências em escolas de ensino fundamental: uma abordagem voltada para física moderna
}

Science sample in Primary Education Schools: A focused approach to modern physics

\author{
H. C. Silva ${ }^{1 *}$; J. S. Ernesto ${ }^{1}$; L. F. A. Aringhieri ${ }^{1}$; F. A. R. Silva ${ }^{1}$ \\ ${ }^{I}$ Faculdade de Física, Universidade Federal do Sul e Sudeste do Pará, 68.505.080, Marabá-Pará,Brasil \\ *h.e.b.cruz@hotmail.com/frolemberg589880@gmail.com \\ (Recebido em 12 de agosto de 2016; aceito em 25 de novembro de 2016)
}

\begin{abstract}
De certa forma, o mundo imediato que cerca o aluno está repleto de objetos e fenômenos que constantemente desafiam a sua compreensão e despertam sua curiosidade. Este artigo relata a construção de uma proposta de se apresentar alguns conceitos de Física Moderna a turmas do último ano de Ensino Fundamental. Optou-se, em ter como base principal uma analise em cima dos PCN's para inserção dos tópicos, em razão de que estes se constituem em uma referência para a transformação de objetivos, conteúdos e didática do ensino. Dando-se uma ênfase especial ao uso de experimentos simples e de baixo custo como recurso metodológico, visto que estes aproximam a vivência direta de alguns dos princípios subjacentes da Física Moderna à tecnologia atual, e proporcionam um caráter lúdico e dinâmico a apresentação. Logo, foi possível observar a percepção que os alunos tiveram em relacionar alguns dos conceitos apresentados com situações comuns do seu dia a dia, reconhecendo que a ciência esta aplicada de maneira efetiva em suas vidas.

Palavras-chave: Material de baixo custo, novas metodologias de ensino, Física Moderna
\end{abstract}

In a way, the immediate world surrounding the student is full of objects and phenomena that constantly challenge their understanding and arouse their curiosity. This article reports the construction of a proposal to present some concepts of modern physics to classes in the last year of elementary school. It was decided, having as main base an analysis on the PCN's for inclusion of topics, on the grounds that these constitute a reference to the transformation of objectives, contents and didactic teaching. Giving yourself a special emphasis on the use of simple experiments and inexpensive as a methodological resource, as these approach the direct experience of some of the underlying principles of modern physics to current technology, and provide a playful character and dynamic presentation. Soon, it observed the perception that students had to relate some of the concepts presented with common situations of your everyday life, recognizing that science this applied effectively in their lives.

Keywords: low coast materials, new teaching methods, modern physics

\section{INTRODUÇÃO}

O ensino de Física no Ensino Fundamental, é normalmente centrado e limitado a conteúdos referentes à Física desenvolvida até meados do século XIX, inicio do século XX, denominada Física Clássica, deixando de lado praticamente toda a Física desenvolvida no decorrer dos séculos XX e XXI, a Física Moderna (FM). Neste trabalho apresenta-se a proposta de se levar alguns conceitos de Física Moderna (FM) a turmas de $9^{\circ}$ ano de escolas publicas na cidade de Marabá, PA. Esta iniciativa deu-se pelo reconhecimento da necessidade de inserção de conteúdos de FM no âmbito escolar. Fato este que vem sendo tema de diversas pesquisas nos últimos anos, e que leva em conta várias justificativas. Destacando-se dentre as muitas, a difusa utilização dos conceitos de FM nas aplicações tecnológicas presentes a quase todo o momento nas nossas vidas [1].

Contudo, sabe-se também, que o currículo escolar não tem acompanhado esse desenvolvimento tecnológico, tornando com isso o ensino de Física cada vez mais defasado em relação ao que acontece no mundo. Vale ressaltar, que comumente o professor depara-se, em sala de aula, com discussões sobre novas descobertas científicas, ou mesmo um novo produto que foi lançado no mercado que gera curiosidade por parte dos alunos do ensino básico, e que sem o 
conhecimento mínimo de FM não há como o professor desenvolver uma discussão a respeito desses temas [2].

Nesse sentido, de acordo os PCN's (Parâmetros Curriculares Nacionais), o aprendizado em Física deve estimular os jovens a este tipo de questionamento. Cabe, no entanto, a própria disciplina fornecer subsídios que permitam o estudante entender e lidar com os fenômenos naturais e tecnológicos que estão contextualizados e vinculados na sua realidade. Dessa forma, o aluno reconhece que a ciência está presente de maneira efetiva em suas vidas, e que esta contribui na compreensão do mundo que o cerca. [3,4]

Nessa percepção, analisando em seus eixos temáticos suas propostas para o $4^{\circ}$ Ciclo $\left(8^{\circ}\right.$ e $9^{\circ}$ ano) do Ensino Fundamental, foram escolhidos alguns tópicos de FM que se encaixam efetivamente naquilo que recomendam para essa etapa, além de outros que não se apresentam claramente expressos, no que neles são propostos. Igualmente, buscou-se uma referencia para ser usada na metodologia, visando introduzir os tópicos da melhor forma possível. Desse modo por apontarem para o uso de uma diversidade de recursos didáticos, destacando para um posicionamento e investimentos em alternativas criativas para alcançar as metas requeridas, optou-se no uso de experimentos simples e de baixo custo, visto que estes aproximam a vivência direta de alguns dos princípios subjacentes da FM aplicados à tecnologia e artefatos atuais.

Além disso, levou-se em conta, o fato de alguns autores apontarem que o uso de atividades experimentais torna o ensino de Ciências um processo dinâmico e motivador, permitindo que o aluno adquira novos conhecimentos e tenha suas ideias prévias questionadas, possibilitando-o também refletir que tudo que existe no cotidiano, na natureza, e nas relações humanas são associadas ao fato ocorrido no experimento proposto. Nesse contexto, autores como Schroeder [5] destacam que essas atividades devem permitir que os jovens interajam com os materiais utilizados, observem o resultado de suas ações e reflitam sobre suas expectativas iniciais, reforçando ou revendo suas opiniões e conclusões. Para Carvalho [6] estas experiências devem proporcionar a transposição do conhecimento aprendido para a vida social, envolvendo as relações existentes entre ciência, tecnologia e sociedade. Desse modo o indivíduo relaciona o fenômeno ocorrido com o mundo que vive e com a cultura em que está inserido, construindo assim sua auto aprendizagem.

O objetivo dessa iniciativa é difundir os conhecimentos científicos referentes a conteúdos de FM por meio da prática experimental. Na pratica, a proposta não consiste necessariamente em tratar cada tópico previamente escolhido de forma minuciosa, na complexidade inerente a esses tópicos. O propósito é aproximar o aluno já no ensino fundamental com conceitos e indagações trazidos pela Física desenvolvida nos últimos dois séculos, visto que, isso comumente não acontece nessa etapa escolar e muitas vezes passam despercebidos ou não são abordados no decorrer da sua vida acadêmica no Ensino Médio. Vale salientar que a intenção em levar essa amostra aos alunos desse nível escolar, é estabelecer também o estreitamento entre a Universidade e a Escola de Ensino Básico, visando dessa forma não apenas apresentar conteúdos aos alunos, e sim, contribuir com os professores atuantes nessas instituições com novas metodologias e ideias, que podem ser usadas na explicação tanto de conceitos referentes à FM, como na de outros conteúdos a nível fundamental ou médio, possibilitando dessa maneira, com o trabalho em conjunto, formar jovens com o pensamento investigativo e motivados a serem conhecedores do mundo em que vivem.

\section{MATERIAL E MÉTODOS}

Para aplicação da proposta do trabalho foram selecionadas 4 escolas de Ensino fundamental com turmas de $9^{\circ}$ ano situadas ao entorno do Campus Universitário II da UNIFESSPA. A escolha e seleção dessas escolas foi feita de maneira aleatória, levando em conta apenas a proximidade delas com a Universidade.

Para apresentação da amostra foram confeccionados alguns experimentos simples e de baixo custo que englobam e facilitam a explicação de fenômenos e dispositivos que estão presentes a quase todo momento ao redor dos alunos, e são baseados em conceitos de FM. 
Os assuntos a serem abordados com uso dos experimentos vão desde conteúdos de ótica, que descrevem o funcionamento do olho humano e como enxergamos as coisas e suas cores, passando pela natureza da luz, decomposição das cores, e a interação da luz com a matéria. Foi também utilizado os conceitos de Relatividade que contextualiza como a ideia de movimento pode ser distinta a partir do ponto de referência, o paradoxo dos gêmeos, curvatura do espaço tempo, e a constância da velocidade da luz, finalizando com a Cosmologia que contempla teorias como a do Big Bang que explicam como surgiu, se estruturou, e evolui o nosso universo.

Foram reproduzidas, experiências como a do disco de Newton, que apesar de ser um experimento clássico, apresenta muito bem algumas propriedades da luz que servem para introduzir os conceitos de FM, ajudando em um melhor entendimento, como é o caso da formação das cores dos objetos. O disco foi feito de forma simples, sendo possível ser facilmente reproduzido por qualquer estudante a nível fundamental. Os materiais usados foram uma folha de papel branca, cd, cola, tesoura, lápis colorido, régua e um ventilador. A Figura 1(Disco de Newton) mostra os materiais usados na confecção, além do disco já pronto e em funcionamento.
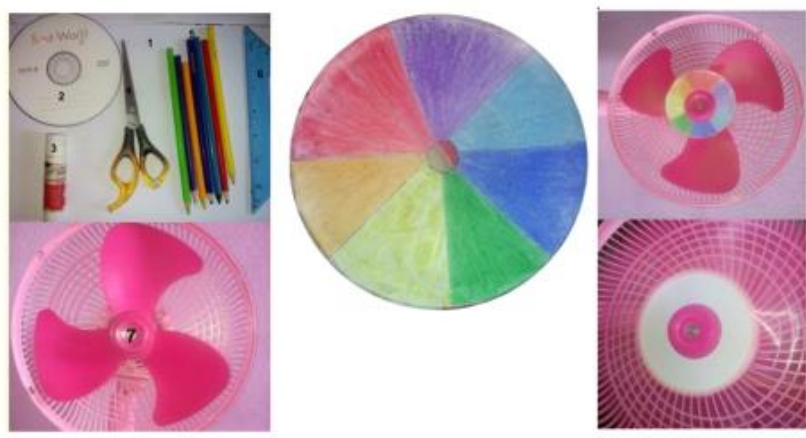

Figura 1: Disco de Newton

Essa experiência foi complementada com o uso de uma simulação bastante simples e ao mesmo tempo bem lúdica, representada na figura 2 (simulação color vison), que permite que o aluno visualize como enxergamos as coisas e suas cores, como funciona o processo da visão, e o porquê da união de todas as cores resultam na cor branca como ilustrado no disco de Newton. Possibilita dessa forma discutir de uma maneira simples, que a luz é formada por pequenas partículas (os fótons).

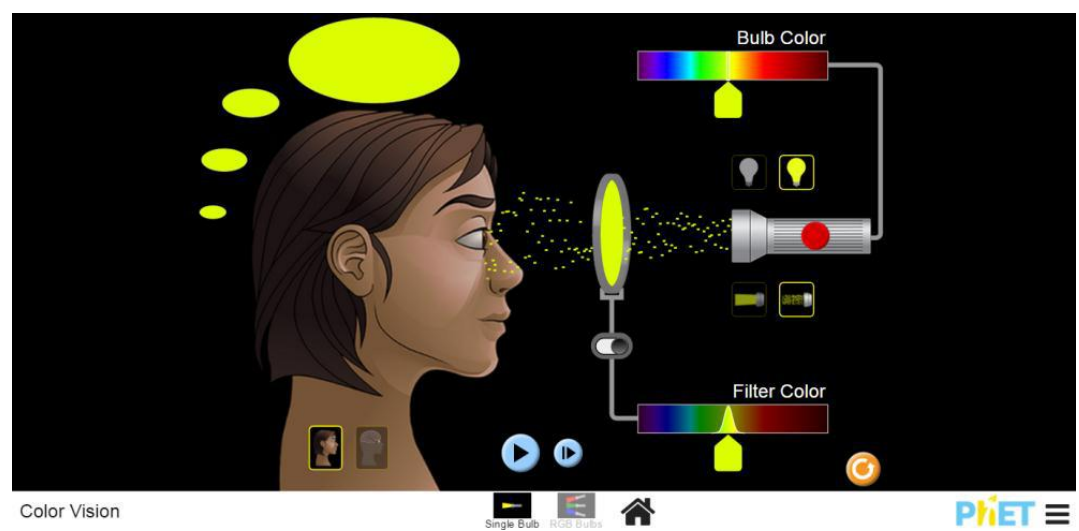

Figura 2: Simulação color vison

Outro experimento produzido, com grande apelo lúdico e podendo ser facilmente reproduzido pelos estudantes, é o da construção de uma lâmpada de luz negra com um aparelho celular. Essa experiência consiste em demonstrar um tipo de luz especial chamada de luz negra, que apesar de não podermos enxergá-la, se aproxima bastante da luz visível. Baseia-se em uma experiência interessante, pois possibilita a compreensão do fenômeno da fluorescência. Esse fenômeno se trata de um tipo de luminescência produzida por alguns materiais quando são iluminados com a luz negra ou radiação ultravioleta. Na montagem desse experimento foram utilizados os seguintes materiais: um aparelho celular com flash, fita adesiva, marcador permanente azul, marcador 
fluorescente, e uma tesoura. A Figura 3 (Lâmpada de luz negra e o efeito da fluorescência) mostra os materiais, o passo a passo da construção da lâmpada de luz negra, e o efeito da fluorescência.

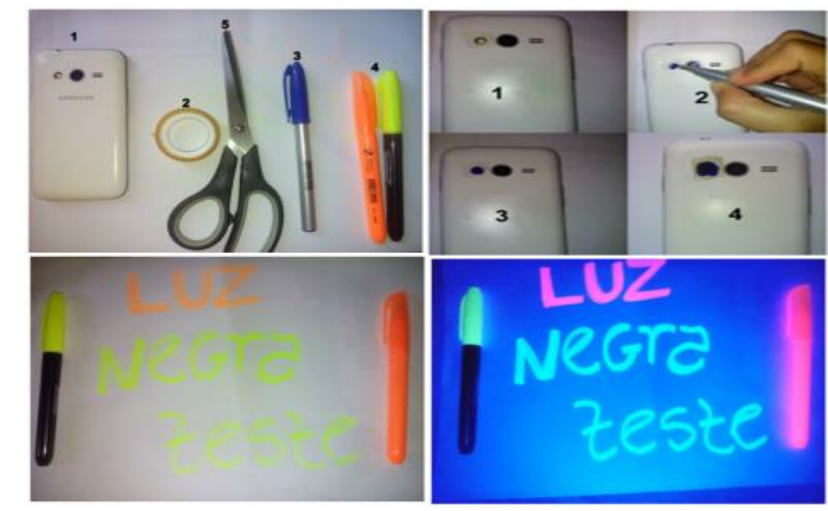

Figura 3: Lâmpada de luz negra e o efeito da fluorescência

Além da fluorescência, foram feitos experimentos que exemplificam outros fenômenos que envolvem a interação da radiação com a matéria, a fosforescência e o efeito fotoelétrico. Estes também são experimentos bastante simples e que aproximam o aluno ao entendimento de situações comuns do cotidiano, tais como o acender e apagar automático das luzes dos postes, e o porquê de alguns materiais brilharem em ambientes escuros. Os materiais básicos para esses experimentos foram, uma tinta fluorescente, placa de madeira, LDR (Resistor que depende da luz), relé, bateria $12 \mathrm{~V}$ e uma lâmpada de LED. A Figura 4 apresenta a forma de demonstração do efeito fotoelétrico e o efeito da fosforescência com o uso da tinta fosforescente.

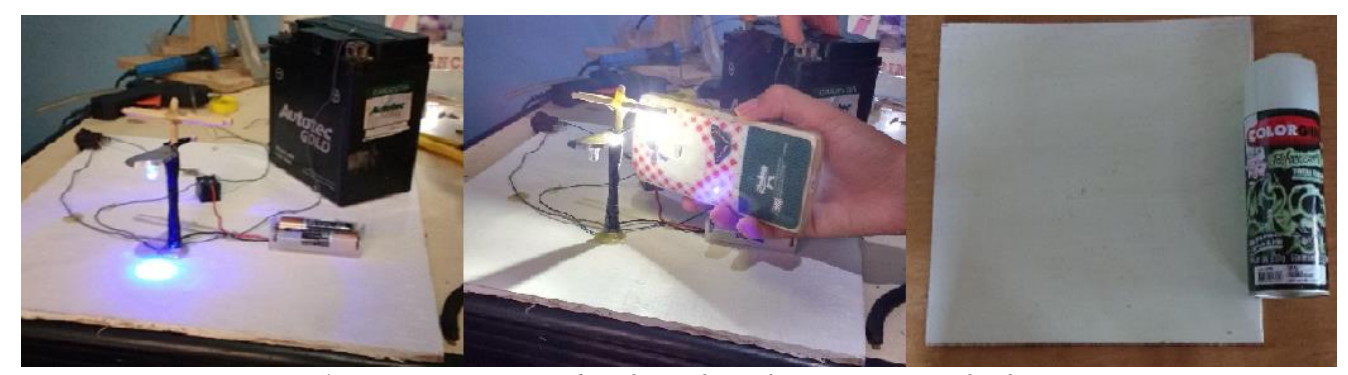

Figura 4: Demonstração do efeito fotoelétrico e tinta fosforescente

No tema Cosmologia foi elaborado experimento que explica a origem e expansão do universo com a teoria do Big Bang. Para isso foram necessários apenas alguns balões, pedacinhos de papel picado e canetinhas. O experimento permite que os estudantes percebam que mesmo com uma pequena explosão é capaz de distribuir matéria a longas e diferentes distâncias, ficando mais fácil a compreensão do porquê de existirem corpos celestes distribuídos em todo o Universo. Possibilita também fazê-los imaginarem a expansão do Universo, a partir da análise de que as galáxias se afastam umas das outras continuamente durante esse processo [7]. A figura 5 (Experiência do Big Bang- explosão e expansão do universo) retrata a execução da experiência.

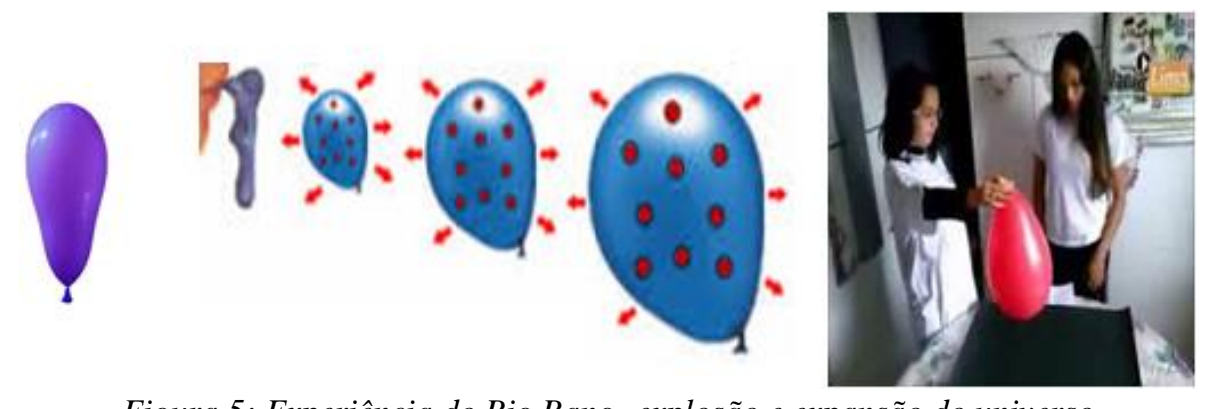

Figura 5: Experiência do Big Bang-explosão e expansão do universo 
Buscou-se também, mostrar como a relatividade explica a gravidade no conceito de espaço e tempo curvo. Sendo requerido, apenas um lençol, uma bola de futebol, e a ajuda de alguns estudantes. Este experimento baseia-se em colocar um objeto esférico de massa equivalentemente grande em um lençol previamente esticado pelos alunos, para que se possa simular a deformação (ou curvatura) do espaço-tempo provocada pela massa do objeto, como sugerido pela Teoria da Relatividade. A figura 6 trata da forma como ocorreu a demonstração da curvatura do espaçotempo.

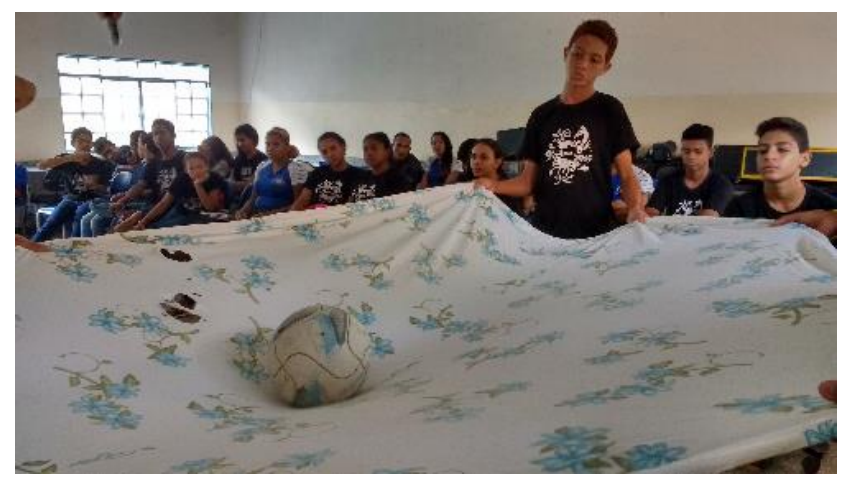

Figura 6: demonstração da curvatura do espaço tempo

Esses experimentos foram selecionados e confeccionados a partir de buscas em livros didáticos, artigos, e sites na internet que apresentavam roteiros de experiências simples e de baixo custo que pudessem ser manipuladas por qualquer estudante a nível fundamental. Além destes, foram pesquisadas algumas imagens e vídeos que contribuíssem no desenvolver da apresentação tornando-a assim, ainda mais lúdica e dinâmica.

Para que se pudesse avaliar a contribuição que a amostra teve sobre o entendimento dos alunos foi aplicado um questionário introdutório. Questionário que foi elaborado com algumas questões objetivas que envolviam conceitos de FM aplicados e envoltos diretamente no cotidiano dos alunos. Em média, na aplicação do questionário, os estudantes responderam todas as questões em um tempo de 15 minutos.

Após a aplicação do questionário, ocorreu a dinâmica de apresentação da proposta pedagógica e a forma como foram abordados consistiu inicialmente na discursão de aspectos relacionados com a luz, fazendo uma reflexão sobre a transição entre a Física clássica e a Física moderna.

Inicialmente foi questionado aos alunos de que forma a luz influenciava o ato de enxergar os objetos e na formação das cores, dessa forma, após responder a essas questões, abordando algumas características da luz na visão da FM com o uso do disco de Newton e da simulação, discutia-se os fenômenos decorrentes da interação desta com a matéria, apresentando aos estudantes os experimentos que relacionavam os conceitos de Fluorescência, Fosforescência e Efeito fotoelétrico. Conceituando, diferenciando e contextualizando cada um deles. Da mesma forma, ocorreram com as explicações dos conceitos vinculados aos tópicos de relatividade e cosmologia, sempre tendo a luz como referência para ser dada a sequência de exibição dos experimentos. Ao final das apresentações de todos os conteúdos, foi reaplicado o mesmo questionário usado no início das apresentações a título de comparação e avaliação do desempenho dos alunos.

Destaca-se, que a escolha deste tipo de avaliação foi considerando o tempo disponível e a duração de cada apresentação. Nesse sentido, toda a aplicação da proposta durou em média 2 horas, que é o período aproximado da carga horária semanal da disciplina nas escolas da rede municipal de Marabá. O objetivo foi adequar da carga horária da disciplina com o da aplicabilidade do projeto, avaliando a viabilidade da inferência metodológica possível à rotina do professor. 


\section{RESULTADOS E DISCUSSÃO}

Analisando-se o questionário após a apresentação dos experimentos, observou-se que os alunos obtiveram uma assimilação significativa sobre os fenômenos e conceitos apresentados. A análise dos dados foi feita a partir da retirada da média aritmética sobre as notas obtidas pelos estudantes de cada escola.

A figura 7 apresenta um gráfico comparando as médias das notas obtidas pelos estudantes ao responderem o questionário antes e após a apresentação da amostra.

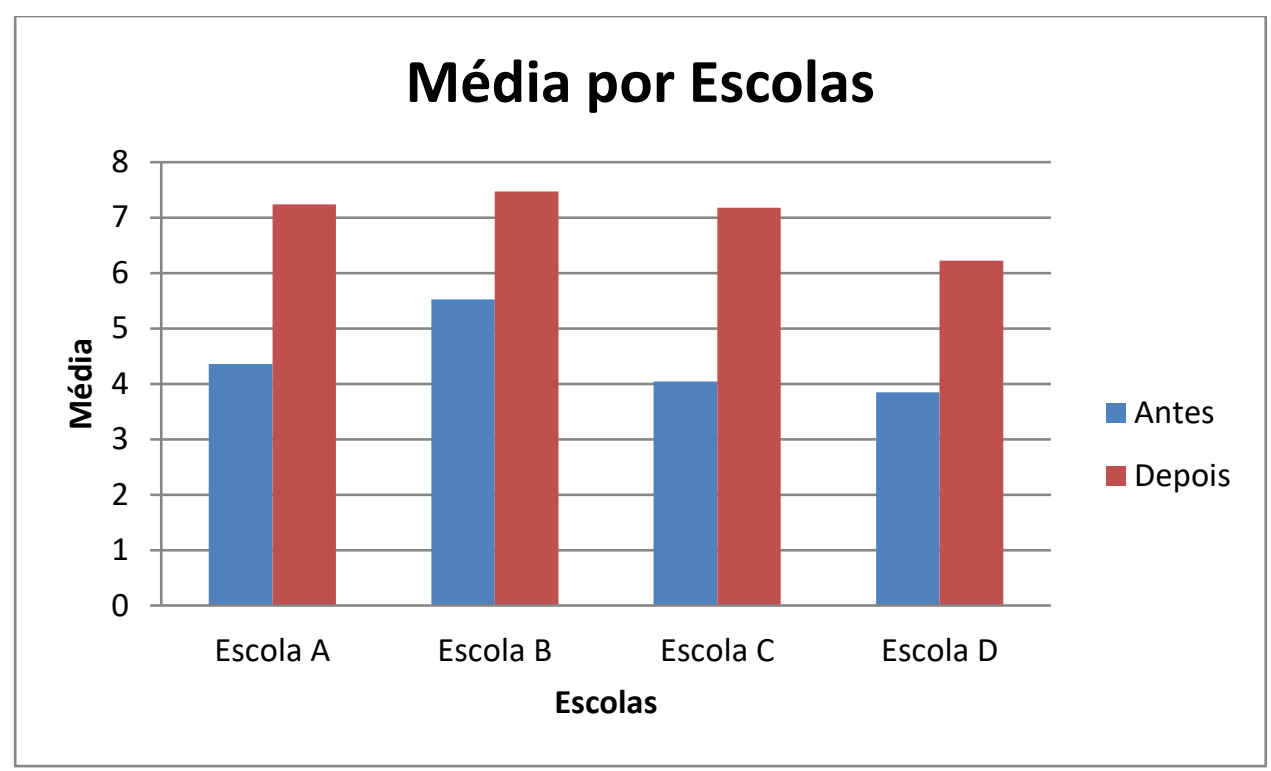

Figura 7: Média de desempenho dos alunos por escolas de acordo a aplicação da proposta pedagógica

Percebe-se claramente com o gráfico acima a contribuição que a amostra teve sobre a concepção dos estudantes em relação aos fenômenos e conceitos abordados nas apresentações que talvez antes não fizessem parte do seu entendimento. Analisando em termos de aproveitamento o colégio A, por exemplo, constatamos nitidamente que houve um rendimento de quase $30 \%$ por parte da média retirada das notas obtidas pelos estudantes após as apresentações. Ficando evidente desse modo, que os alunos conseguiram assimilar e reconhecer os conceitos apresentados com o que se discutia nos questionários.

Verificou-se durante as apresentações, um grande interesse em interagir com as experiências, em grande parte, por sua grande simplicidade de elaboração e explicação. A experiência da luz negra, com o fenômeno da fluorescência, foi o que mais os entusiasmou o público alvo em sua reprodução. Outro experimento em que houve um grande envolvimento com a participação na demonstração foi o que transmitia a ideia de espaço e tempo curvo com o lençol. Destaca-se também, através da análise qualitativa, a reação dos alunos, a percepção que eles tiveram em relacionar alguns dos conceitos apresentados com situações comuns do seu cotidiano, ficando claro o reconhecimento de que a ciência esta aplicada de maneira efetiva em suas vidas a partir do interesse dos alunos no conhecimento elaborado mostrado pelas etapas de construção das experiências, proporcionando o aumento do índice de avaliação formativa do conteúdo. A contra ponto, cabe ressaltar, de forma qualitativa, uma analise do baixo índice de envolvimento do corpo docente das escolas envolvidas, esperava-se que houvesse uma troca de informações, uma comparação da forma como estes aplicam a sua metodologia de ensino com a forma de como a proposta da pesquisa foi apresentada na escola, levando-se em consideração todos os problemas existentes em torno das escolas de ensino básico. 


\section{CONCLUSÃO}

Os resultados obtidos com apresentação mostram como esse tipo de iniciativa pode contribuir com o aprendizado dos alunos, não só no que diz respeito a conceitos de FM, e sim nos conteúdos envoltos nas diversas áreas de ensino fundamental e médio. Um fator importante é o estreitamento da relação entre as universidades com as escolas de ensino básico, promovendo assim, um compartilhamento de saberes e ideias, possibilitando ao professor do ensino primário e médio estar mais próximo do desenvolvimento de novas pesquisas de ensino na área de ciências.

Numa análise quantitativa, pode-se verificar o aumento no nível de desempenho em termos da aprendizagem em todas as escolas em que a proposta foi aplicada, o rendimento dos alunos deu um salto de qualidade de quase $30 \%$, o que mostra a eficiência do método. De forma qualitativa pode ser ver na interação dos alunos, o envolvimento, os questionamentos, as discussões, o monte de hipóteses levantadas por eles na busca de encontrar as diversas soluções para os seus questionamentos.

Pelo caráter dinâmico desse tipo de metodologia ativa, em que, o grande desafio é fazer o discente se tornar um ser ético, crítico, reflexivo, possibilitando a construção de uma rede de mudanças sociais com a consequente expansão da consciência individual e coletiva é que acreditamos numa mudança radical entre o paradigma da metodologia tradicional e moderna, tornando assuntos, como o de Física Moderna, algo muito atraente independente do nível de escolaridade.

\section{REFERÊNCIAS BIBLIOGRÁFICAS}

1. Neves da Silva JR, Fusinato PA, Lino A. A importância da abordagem conceitual no ensino de física moderna e contemporânea no ensino médio: experiência em um curso introdutório de física quântica. Revista Ciência \& Ideia. 2013 Jan-Dez, Vol. 4, n. 2, pág. 1-8.

2. Oliveira FF, Viana DM, Gerbassi RS. Física moderna no ensino médio: o que dizem os professores. Revista Brasileira de Ensino de Física. 2007 v. 29, n. 3, p. 447-454.

3. BRASIL, Secretaria de Educação Fundamental. Parâmetros curriculares nacionais: ciências naturais. Ensino de quinta a oitava séries. Brasília: MEC/SEF. 1998. 138 p.

4. BRASIL, Secretaria de Educação Fundamental. Parâmetros curriculares nacionais (PCNs): introdução aos parâmetros curriculares nacionais. Ensino de primeira a quarta série. Brasília: MEC/SEF, 1997. 126 p.

5. Schroeder C. Uma proposta para a inclusão da física nas séries iniciais do ensino fundamental. Revista Experiências em Ensino de Ciências. 2006 V1(1), pp.23- 32.

6. Carvalho AMP; As praticas experimentais no ensino de Física. In: Carvalho, A MP de, et al. (Orgs.) "Ensino de Física" Coleções ideias em ação. São Paulo: Cengage Learning; 2010. Capitulo 3, as práticas experimentais no ensino de Física. p. 53-78.

7. Valio, ABM, et al. Ser protagonista: Física $3^{\circ}$ ano: ensino médio. São Paulo: Edições SM, 2013, $2^{\mathrm{a}}$ ed. 